The Open Materials Science Journal
CrossMark
Content list available at: www.benthamopen.com/TOMSJ/
DOI: $10.2174 / 1874088 \mathrm{X} 01610010008$

RESEARCH ARTICLE

\title{
Failure Analysis of Cracking on Side Tooth Gingivae of a Percussive Drill Bit
}

\author{
Zhao Tianliang $^{1}$, Liu Zhiyong ${ }^{1,2, *}$, Du Cuiwei ${ }^{1}$, Dong Chaofang ${ }^{1}$ and Li Xiaogang ${ }^{1}$ \\ ${ }^{I}$ Corrosion and Protection Center, University of Science and Technology Beijing, Beijing 100083, China \\ ${ }^{2}$ Key Laboratory of Chinese Ministry of Education for Corrosion and Prevention, Beijing 100083, China
}

Received: January 15,2015

Revised: September 26, 2015

Accepted: September 29, 2015

\begin{abstract}
Failures of percussive drill bits have been attributed to the external mechanical force and structural design by engineers and researchers for a long time. Few attentions have been focused on the material itself. Generally, it is the unqualified material, induced by the improper metallurgy and heat treatment process, which makes the drill bits fail soon after they are put into service. Reasons of the crackings on side tooth gingivae of a drill bit, which failed prematurely at the beginning of the service, were analyzed comparatively. Scanning electron microscope, metallographic observation, mechanical performance test and chemical composition analysis were adoptedfor the failure analysis. Results show that microstructure, chemical composition and mechanic properties of the substrate were excluded from the reasons of the cracking. It is mainly the excessive inclusions and defects in the carburized layer which induced the inhomogeneity of material organization and performance. Those inclusions and defects act as stress concentrators and leading to the crack initiation. In addition, toughness of the carburized layer is also decreased due to its over-carburization. It makescracks more easily initiate from the carburized layer and then propagate into the substrate under the stress of interference fit.
\end{abstract}

Keywords: Carburized layer, Cracking, Failure analysis, Percussive drill bit, Side tooth gingiva.

\section{INTRODUCTION}

Air impact rotary drilling technology has been widely applied in mining, construction, oil and gas drilling [1]. Due to its working mechanism, a combination of impact and rotation, and high drilling speed, the bits bear great cyclic impact load, serious abrasion wear, heavy torsion load and etc. [2,3]. During past decades money counted by millions of dollars and plenty of time have been spent to replace the failed component [4]. It increases the cost of drilling dramatically. Therefore, efforts have been made to prolong their service life such as using drill tooth of better mechanical properties. Although that, failures still happen a lot due to the synergism of its complex work status and metallurgic and technical factors.

To prolong the service life, reasons of failure should be correctly identified first. It has been reported considerably about the failure analyses of drill bits. Failure forms of drill bits and the corresponding reasons are mostly discussed and concluded. According to previous reports [2, 4 - 13], failure forms of drill bits mainly present as tooth loss, tooth fracture, tooth wear and cracking of drill body. Analyses of failure reasons corresponding to different failure forms are also given in most literatures [5 - 12]. Although the reasons are different, most of the literatures attribute them to the external mechanical force and structural design [5, 10 - 13]. Problems about the material are always insufficiently considered in the failure reasons of drill bits [14]. Actually numerous failure reasons come from the metallurgy and heat treatment process which will have a tremendous influence on mechanical properties of the material. So it makes much sense to get an insight into the material itself for failure reasons.

In this paper, a batch of percussive drill bits were found cracking on side tooth gingiva. They cracked before they

\footnotetext{
* Address correspondence to this author at the Corrosion and Protection Center, University of Science and Technology Beijing, Beijing 100083, China; Tel: +86-10-62333931-502; E-mail: dcw@ustb.edu.cn
} 
were put into service. We called it the unqualified (hereinafter, the unqualified). Correspondingly, the one which normally scraped after serving for a long time is called the qualified (hereinafter, the qualified). Obviously, the unqualified cracked not because of the external mechanical force or the structural design., This paper comparatively analyzed chemical composition, fracture morphology and mechanical properties of the unqualified and the qualified. It tried to found the failure reasons from the perspective of the material and the manufacturing process.

\section{MATERIALS AND METHODS}

\subsection{Materials}

Both the qualified and unqualified drill bit bodies are made of 25SiMnCrNi2Mo high-strength alloy. Their chemical compositions are listed in Table 1. It shows that tiny differences on chemical composition exists between the unqualified and the qualified. So chemical composition of the unqualified can be viewed as in normal fluctuation range.

\subsection{Methods}

\subsubsection{Scanning Electron Microscopy}

A QUANTA 250 scanning electron microscope (SEM) was used to observe cracks and fracture wall on the side tooth gingiva, using a voltage of $20 \mathrm{kV}$. Based on the results, crack initiation and propagation path was studied.

\subsubsection{Optical Microscopy}

A KEYENCE 2000 microscope was used to observe metallographic structures of the substrate, the carburized layer and the surface around the main crack. Samples were etched for 10 seconds using 4\% HNO3 + alcohol solution before the observation. Based on the results, microstructural differences between the qualified and the unqualified were discussed.

Table 1. Chemical composition of the drill bits.

\begin{tabular}{|l|c|c|c|c|c|c|c|c|c|}
\hline Elements & $\mathbf{C}$ & $\mathbf{M n}$ & $\mathbf{M o}$ & $\mathbf{C r}$ & $\mathbf{N i}$ & $\mathbf{P}$ & $\mathbf{S}$ & $\mathbf{S i}$ & $\mathbf{F e}$ \\
\hline The unqualified & 0.27 & 1.45 & 0.62 & 0.27 & 1.58 & 0.010 & 0.004 & 1.68 & $\mathrm{Bal}$ \\
\hline The qualified & 0.28 & 1.48 & 0.62 & 0.32 & 1.41 & 0.013 & 0.006 & 1.67 & $\mathrm{Bal}$ \\
\hline
\end{tabular}

\subsubsection{Tensile Test}

A Letry WDML-3 testing machine was used to test tensile properties of the drill bit body. Tests were carried out in accordance with GB 228-87 standard. Based on the results, differences of tensile properties between the qualified and the unqualified were discussed.

\subsubsection{Charpy Impact Test}

A WANCE PIT pendulum impact testing machine was used to test impact absorbed energy of the drill bit body. The tests were carried out in accordance with GB/T229-2007 standard. Based on the results, differences of impact performance between the qualified and the unqualified were discussed.

\subsubsection{Rockwell Hardness Test}

A JINSHI HR-150 Rockwell hardometer has been used to test the hardness distribution from the surface to the internal along the radial direction. The tests were carried out in accordance with GB/T230.1-2009 standard. Based on the results, homogeneity and quenching degree along the radial direction of drill bit body were studied.

\subsubsection{Hydrogen Content Measurement}

Considering that 25SiMnCrNi2Mo, as high-strength steel, usually shows great sensitive to hydrogen embrittlement, it will be necessary to determine whether hydrogen play a major role in the cracking or not. Infrared absorption method was applied to test hydrogen contents in the drill bits. Samples were cut from the surface layer near the cracks. Hydrogen contents in those samples were detected by using TCH-600 oxygen nitrogen hydrogen analyzer produced by LECO Company. 


\section{RESULTS AND DISCUSSION}

\subsection{Observation of Cracks}

As shown in Fig. (1), cracks form on the tooth gingivae along the axial direction of the drill bit. Obviously, there are few signs of wear on it. it indicates that cracks formed before the drill bit was put into service. That is why we call it the unqualified drill bit. Fig. (2) shows the image of another worn-out drill bit. Conversely, cracks are not found on the counterpart of the worn one. We call it the qualified. It is also seen from Fig. (1) that crack line is very straight and fracture wall is vertical to the surface. It indicates that the tensile stress along the circumference direction induced by interference fit may directly respond for the crack initiation. However, there should be no difference of this stress between the unqualified and the qualified due to their identical interference fits. Therefore, whether the cracks are induced by excessive interference fit value or not still needs further investigations.

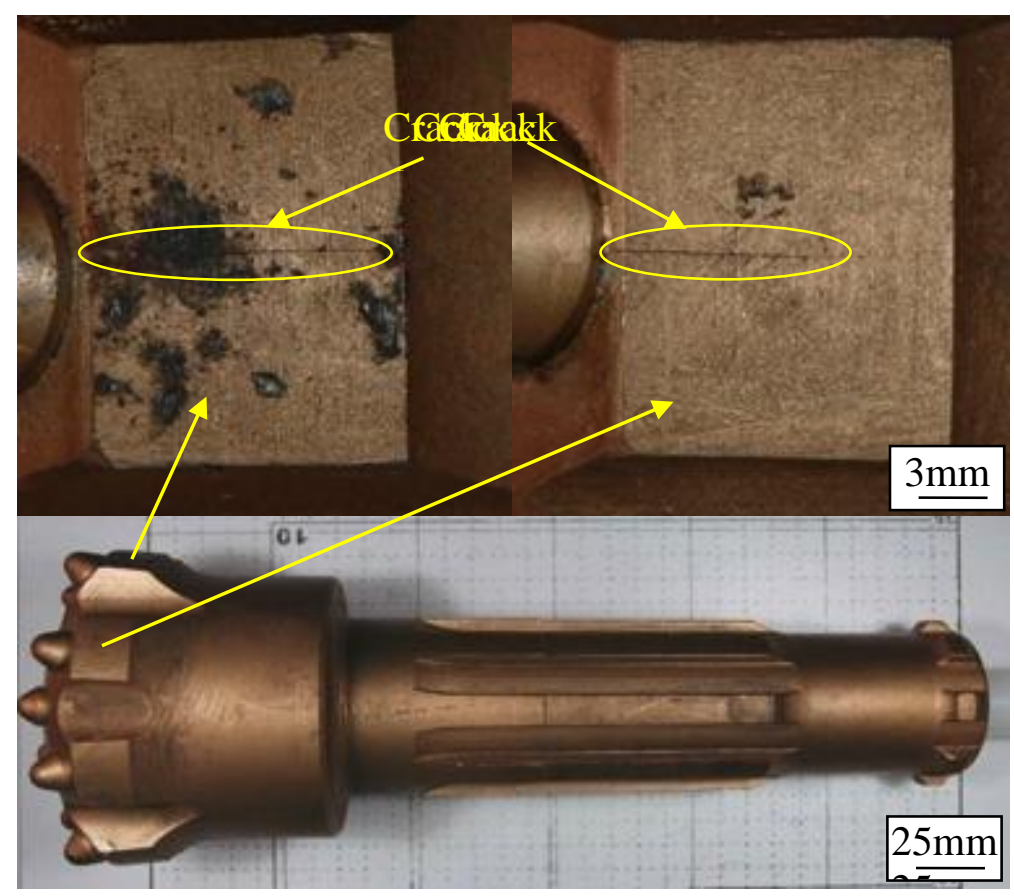

Fig. (1). Cracks on the side tooth gingiva of the unqualified drill bit.

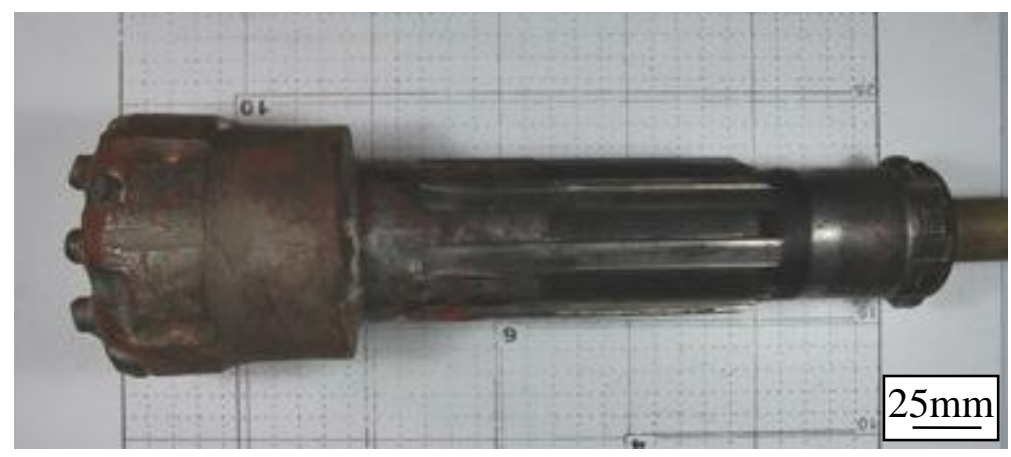

Fig. (2). The qualified drill bit scrapped after serving for a long time.

Micro-observations have been performed on the cracks and fracture wall by using SEM. Fig. (3a) is taken from the perspective of side face of the unqualified. It is seen that main crack propagates from the outside surface into the substrate and some small cracks initiate on the alveolus side. Fig. (3b) shows overall appearance of the fracture wall. Arc textures can be seen on the fracture wall. Based on those textures, origin and propagation direction of the main crack can be determined. As shown in Fig. (3b), the main crack initiates at the corner between A and B and propagates along the direction vertical to the arc textures. The plain fracture surface indicates that the cracking is characterized with embrittlement feature. 

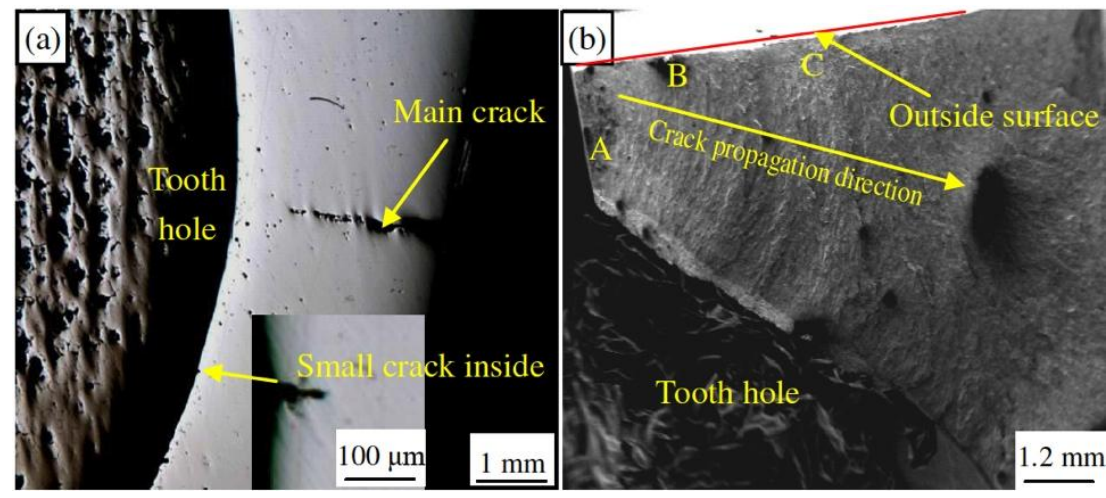

Fig. (3). (a) Cracks and (b) fracture wall on the side tooth gingiva.

Fig. (4) shows microstructure of the fracture surface. Figs. (4a-4c) are respectively taken from places marked by A, C, B in Fig. (3a). It can be seen from them that excessive dark dots (Fig. 4a) and reticulation (Fig. 4b) and some loosens (Fig. 4c) distribute on the fracture wall near the outside surface. Fig. (4a) clearly exhibits that surface of the drill bit has been carburized. The gray area, which is apparently distinct from the white substrate, is identified as the carburized layer. Those dark dots and reticulation on it are believed to be the carbon-rich regions. Generally, they can be seen as harmful defects when they are not uniformly distributed. Fig. (4c)shows some loosens accompany those carbon-rich regions. All of them act as stress raisers and make the carburized layer risk crack initiation seriously under a uniaxial stress, which is especial for the high-strength steel [14 - 16].
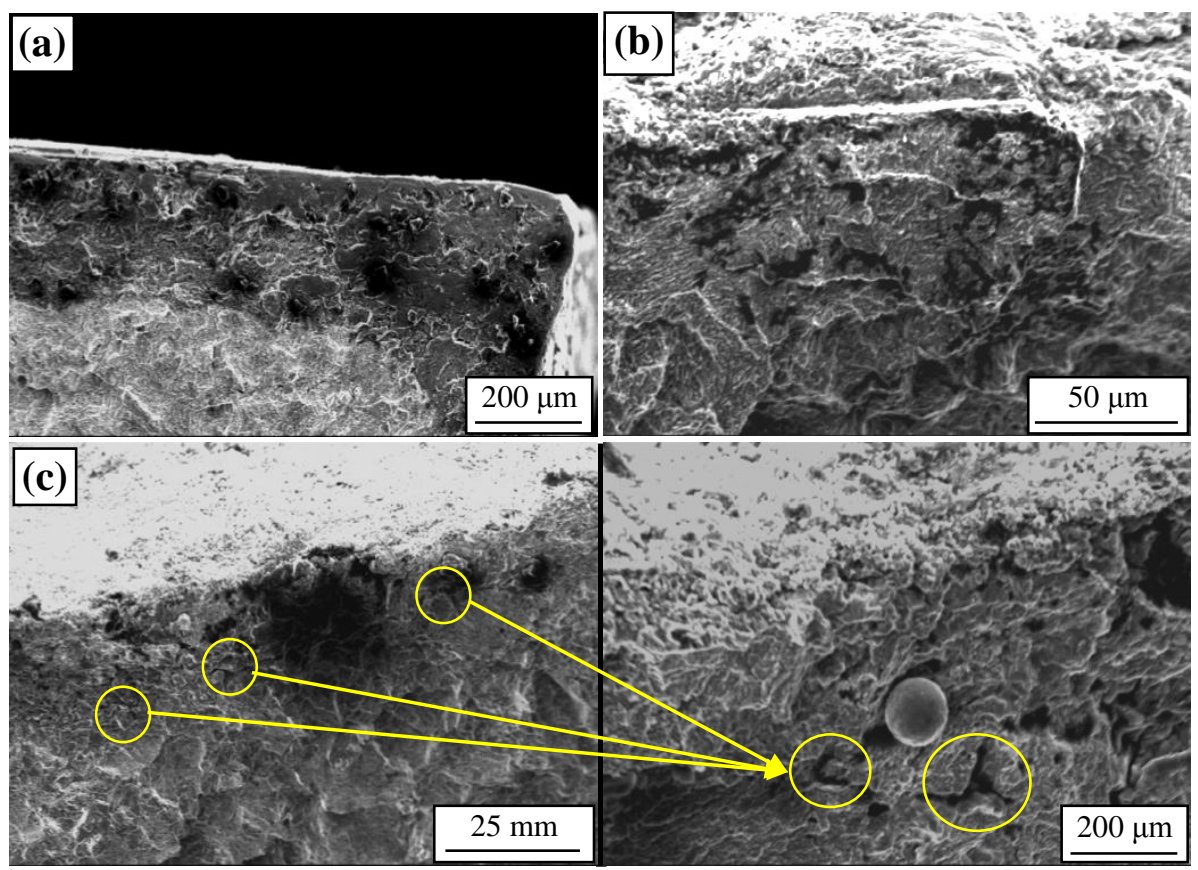

Fig. (4). Defects in the carburized layer: (a) carbon-rich dots, (b) carbon-rich reticulations, (c) loosens.

\subsection{Metallographic Observation}

Images shown in Fig. (5) are metallographic structure of the substrate. Few differences of metallographic structure can be seen between the unqualified (Fig. 5a) and the qualified (Fig. 5b). They are both relatively pure acicular bainite, or it may be martensite due to high carbon content. It indicates that the cracking should not initiate from the substrate. Fig. (6) shows that numerous dark dots are dispersed in the carburized layer of the unqualified, which is barely seen in that of the qualified. Those dots represents the structural or/and compositional inhomogeneity, such as the carbon-rich dots. They are far denser than that in the substrate. It is consistent with what is seen in Fig. (4a). 

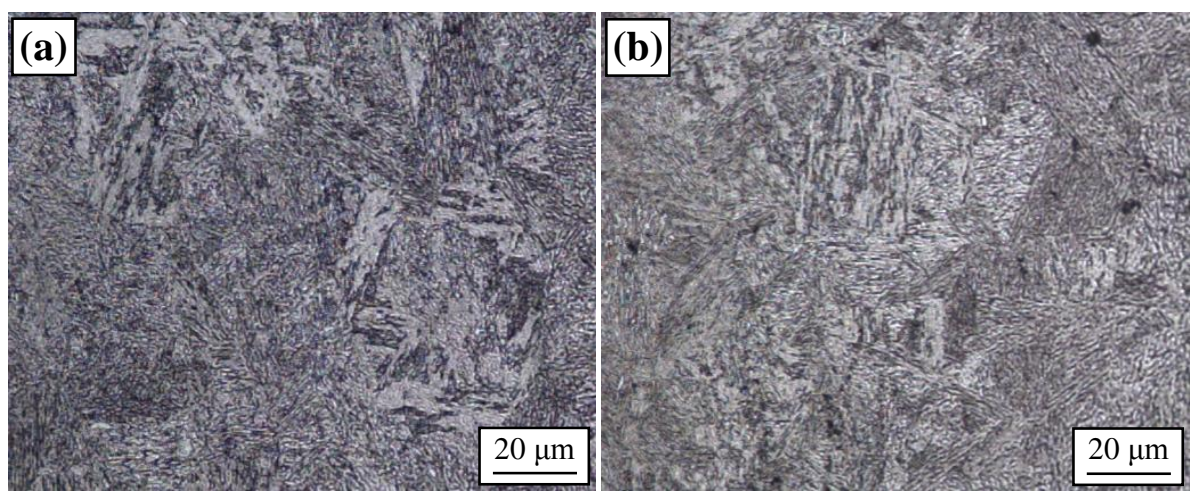

Fig. (5). Metallographic structure of the substrates of (a) the unqualified and (b) the qualified respectively.
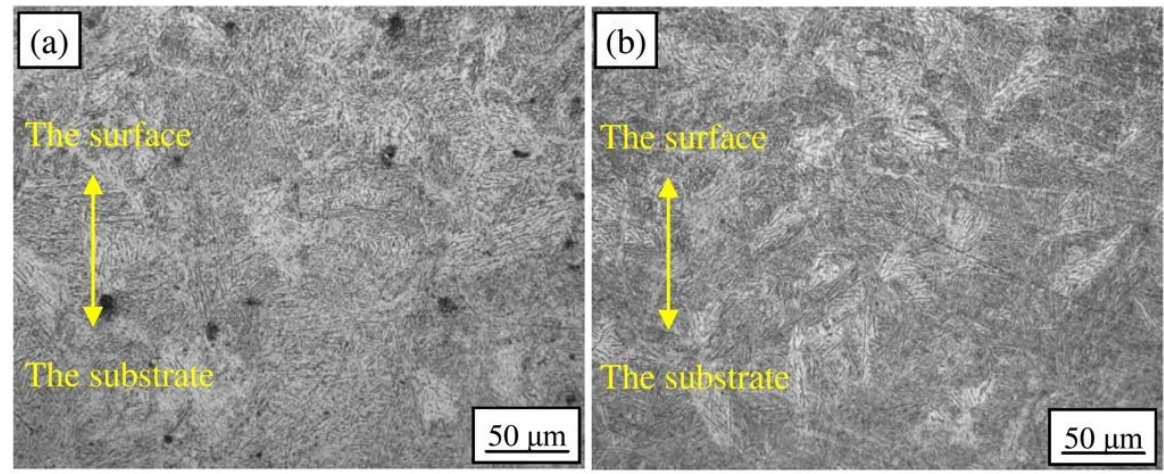

Fig. (6). Metallographic structure of the carburized layers of (a) the unqualified and (b) the qualified respectively.

Metallographic observations have also been taken on the surfaces of the qualified and unqualified. The results are shown in Fig. (7a) shows that almost entire surface of the unqualified is blackened. Comparatively, that is much lighter on the surface of the unqualified, as shown in Fig. (7b). As they are etched in the same solution for the same time, this difference should not be induced byethcing. It indicates that the unqualified has been over-carburized more seriously than the qualified.
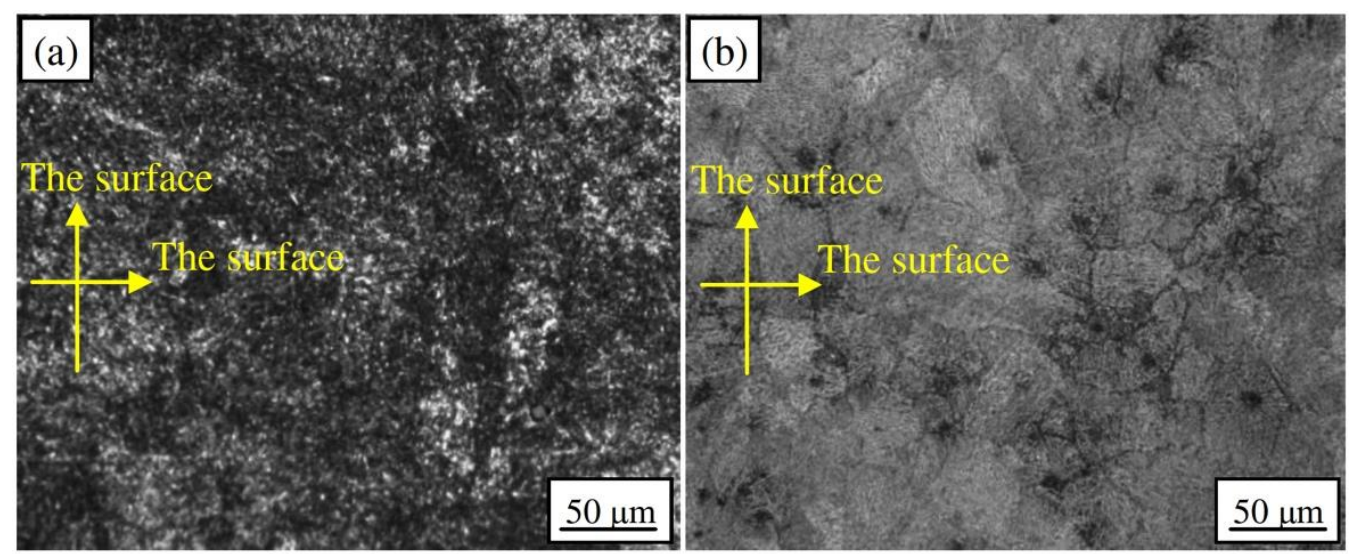

Fig. (7). Metallographic structure of the surfaces of (a) the unqualified and (b) the qualified repectively.

\subsection{Tensile Test}

Three parallel tensile samples have been cut from the substrate of the unqualified and qualified drill bits respectively. The test results are listed in Table 2 . It can be seen that elongation rate of the unqualified is $1.5 \%$ lower than that of the qualified and yield strength of the unqualified is about $100 \mathrm{MPa}$ more than that of the qualified. It means that the unqualified is of a worse ductility than the qualified does. 


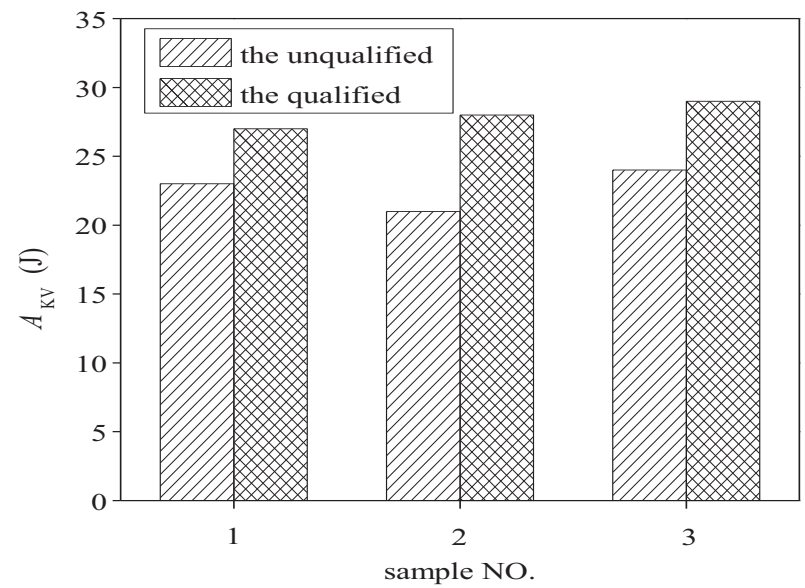

Fig. (8). Impact absorbing energy of the unqualified and the qualified drill bit.

\subsection{Charpy V-notch Impact Test}

Fig. (8) shows the charpy impact absorbed energy of three parallel V-notch samples cut from the unqualified and qualified respectively. Impact absorbed energy $\left(A_{\mathrm{KV}}\right)$ of the unqualified is about $20 \%$ on average lower than that of the qualified. It manifests that resistance to impact fracture of the unqualified deteriorate when compared to that of the qualified. But the degree is not great enough.

Table 2. Tensile propertiess of the unqualified and the qualified.

\begin{tabular}{|c|c|c|c|c|c|}
\hline & Serial No. & $\mathbf{T} /{ }^{\circ} \mathbf{C}$ & Tensile Strength/MPa & Yield Strength/MPa & Elongation Rate $/ \%$ \\
\hline \multirow{3}{*}{ The qualified } & 1 & \multirow{3}{*}{23} & 1420 & 770 & 15.0 \\
\hline & 2 & & 1420 & 725 & 16.5 \\
\hline & 3 & & 1410 & 780 & 13.5 \\
\hline \multirow{3}{*}{ The unqualified } & 1 & \multirow{3}{*}{23} & 1400 & 860 & 13.0 \\
\hline & 2 & & 1400 & 850 & 12.0 \\
\hline & 3 & & 1410 & 855 & 15.5 \\
\hline
\end{tabular}

\subsection{Rockwell Hardness Test}

Fig. (9) shows the hardness distribution along the radial direction from the surface into the substrate. It indicates that hardness of the qualified is generally lower and distributes more uniformly than that of the unqualified. The inhomogeneity on hardness distribution reflects the inhomogeneity on internal residual stress and microstructure. Actually, difference between them is still in a rational range which can be taken as error of measurement. Besides, all of the five test points are located in the substrate. It indicates that the substrate of the unqualified possesses internal residual stress and microstructure similar to the substrate of the qualified. That is consistent with what is illustrated in Fig. (5).
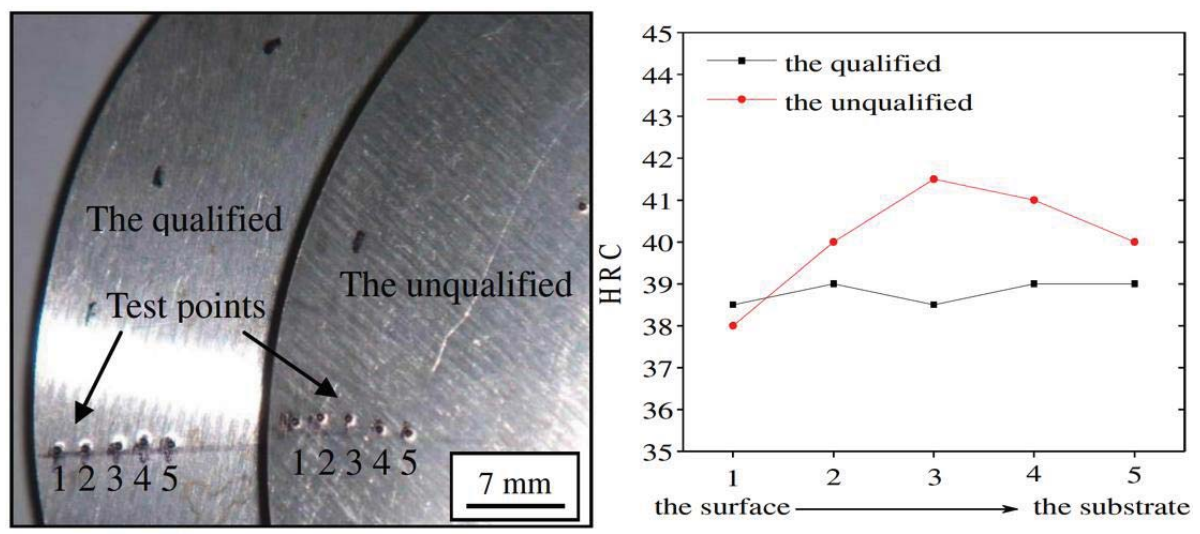

Fig. (9). Hardness distribution along the radial direction from the surface into the substrate. 


\subsection{Hydrogen Content Analysis}

Hydrogen contents of the carburized layers of the unqualified and qualified are shown in Table 3. It can be seen that both of them are less than one ppm. The unqualified contains even less hydrogen content than the qualified does. It proves that hydrogen in the carburized layer is not responsible for the cracking of the unqualified.

\subsection{Theoretical Calculation}

\subsubsection{Stress Status and Crack Initiation}

The drill teeth and the tooth holes are fastened by interference fit. Due to the different positions and asymmetry of tooth holes, tensile stress caused by interference fit generates a complex stress field at end face of the drill bit. According to previous study, the tensile stress level around the side teeth is much higher than that around the interior teeth [17]. Stress status on the edge of the end face nearby side teeth is simplified to the sketches shown in Fig. (10). The stress that the carburized layer suffered $\left(\sigma_{\mathrm{c}}\right)$ is much greater than the stress that the substrate suffered $\left(\sigma_{\mathrm{b}}\right)$. In addition, structure of the carburized layer is more defective than that of the substrate (see Figs. 5a, 6a). Greater stress and more defects make the carburized layer more likely initiate crack than the substrate do. Moreover, the stress concentration caused by structure asymmetry of fracture surface will further promote the crack initiation.

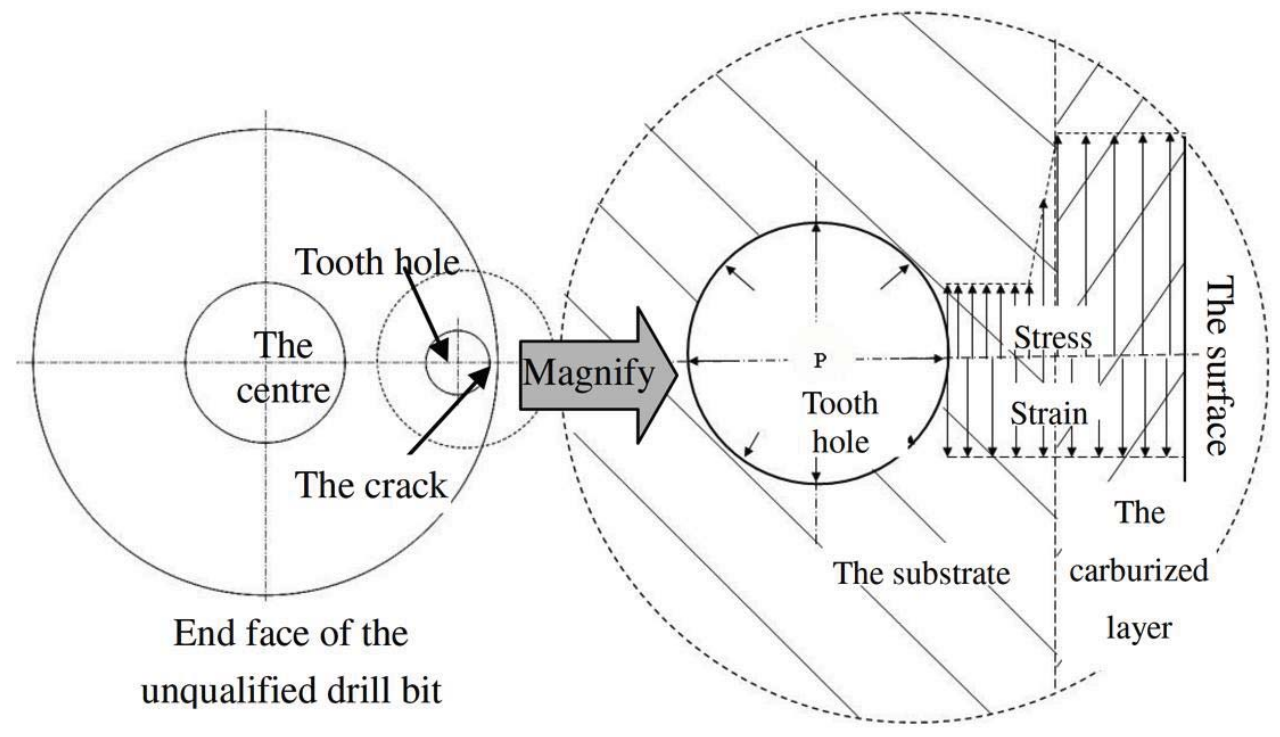

Fig. (10). Sketch of stress status around the crack on the edge of side tooth.

Table 3. Hydrogen contents of the surface layers of the unqualified and the qualified respectively.

\begin{tabular}{|l|c|c|}
\hline & Serial No. & Hydrogen Content \\
\hline \multirow{2}{*}{ The unqualified } & 1 & 0.15 \\
\cline { 2 - 3 } & 2 & 0 \\
\hline \multirow{2}{*}{ The qualified } & 1 & 0.2 \\
\cline { 2 - 3 } & 2 & 0.4 \\
\hline
\end{tabular}

\subsubsection{Fracture Mechanical Analysis}

As discussed above, crack is initiated from the carburized layer due to more defects (actually carbon-rich regions and loosens) contained in the carburized layer than in the substrate. Nevertheless, how crack is initiated from the carburized layer and propagates to the substrate still lacks theoretic support. This will be given in the following paragraphs.

A stress unit, which contains defects, is taken out from the carburized layer as a mechanical unit in order to analyze the stress status around those defects. Those defects including carbon-rich dots and reticulations and loosens can be 
seen as ellipse particles. Fig. (11) illustrates the sketch of the stress unit. The radial stress can be ignored when compared with the much greater circumferential stress $\sigma$. The length of long axis is $2 a$ and the distance between them along the axial direction is $2 b$. According to fracture mechanics [18], fracture toughness of the carburized layer, $K_{\mathrm{ICc}}$, can be expressed as follows:

$$
K_{1 \mathrm{Cc}}=\sigma \cdot \sigma_{\mathrm{sc}}(\pi a)^{2}
$$

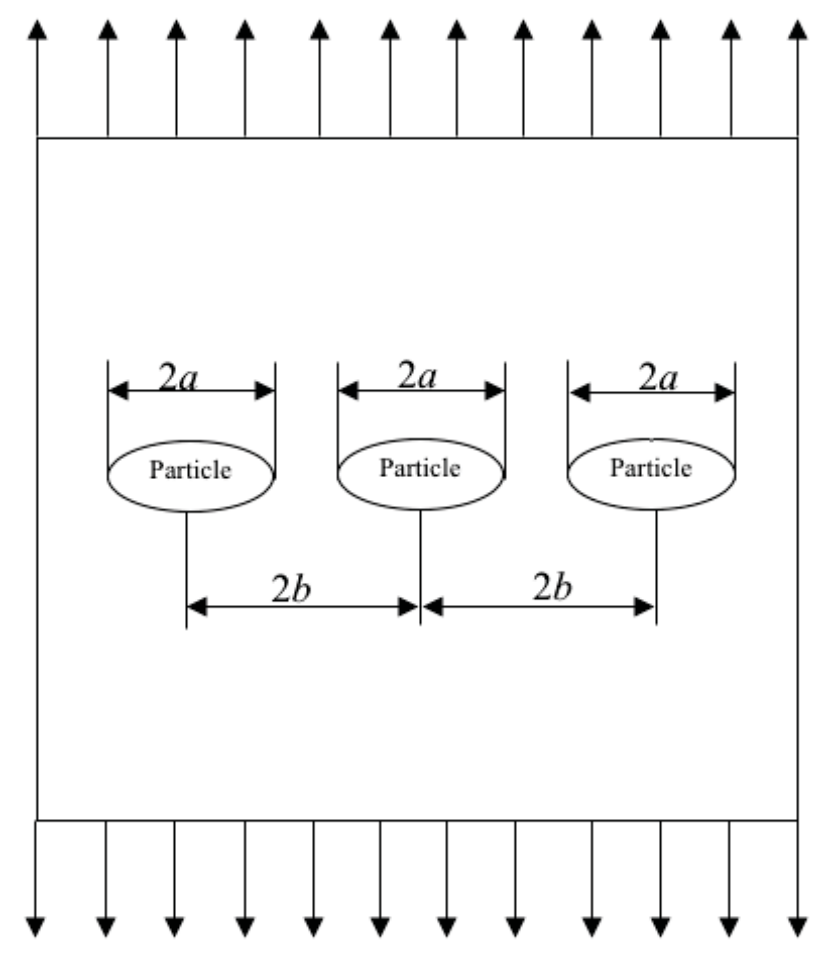

Fig. (11). Stress unit containing defects in the carburized layer of the unqualified.

where $\sigma_{\mathrm{sc}}$ is yield strength of the carburized layer; $\alpha$ is the shape factor which is related to the shape of particles and expressed in equation (1) $)$.

$$
\alpha=\sqrt{\frac{2 b}{\pi a} \operatorname{tg}\left(\frac{\pi a}{2 b}\right)}
$$

It can be estimated from Fig. (5a) that value of $\mathrm{b}$ is $60 \mu \mathrm{m}$ and value of $a$ is $20 \mu \mathrm{m}$. Then value of $\alpha$ can be calculated out to be 1.05 and equation (1a) becomes:

$$
K_{\mathrm{ICC}}=1.05 \sigma_{\mathrm{sc}}(\pi a)^{2}
$$

As carbon content of the carburized layer is greater than that of the substrate, it is deemed that yield strength of the former is greater than that of the later. Then yield strength of the former can be assumed to be 1.0, 1.25, 1.5, 2.0 and 2.5 times of that of the laterwhich is about $855 \mathrm{MPa}$ (see Table 2). Value of $K_{1 \mathrm{cc}}$ calculated out by substituting values of $\sigma_{\text {sc }}$ into equation (2). The results are listed in Table 4. $\sigma_{\mathrm{sb}}$ is the yield strength of the substrate. It can be seen that the carburized layer is of very low fracture toughness so that crack can be easily initiated and propagate in the carburized layer.

Table 4. Fracture toughness of the carburized layer under different ratios of $\sigma_{\mathrm{sc}} / \sigma_{\mathrm{sb}}$.

\begin{tabular}{|l|c|c|}
\hline $\boldsymbol{\sigma}_{\mathrm{sc}} / \boldsymbol{\sigma}_{\mathrm{sb}}$ & $\boldsymbol{\sigma}_{\mathrm{sc}} / \mathbf{M P a}$ & $\mathbf{K}_{\mathrm{ICc}} / \mathbf{M P a} \cdot \mathbf{m}^{\mathbf{1 / 2}}$ \\
\hline 1.0 & 855 & 5.03 \\
\hline 1.25 & 1068 & 6.29 \\
\hline
\end{tabular}


(Table $\square$ \) contd......

\begin{tabular}{|l|c|c|}
\hline $\boldsymbol{\sigma}_{\mathrm{sc}} / \boldsymbol{\sigma}_{\mathrm{sb}}$ & $\boldsymbol{\sigma}_{\mathrm{sc}} / \mathbf{M P a}$ & $\mathbf{K}_{\mathrm{ICc}} / \mathbf{M P a} \cdot \mathbf{m}^{\mathbf{1 / 2}}$ \\
\hline 1.5 & 1282 & 7.55 \\
\hline 2.0 & 1710 & 10.06 \\
\hline 2.5 & 2137 & 12.58 \\
\hline
\end{tabular}

When the crack penetrates the carburized layer and reaches the substrate, the cracking part can be seen as a finitewidth tensile plane model with a unilateral crack. Then fracture toughness of the substrate, $K_{1 \mathrm{Cb}}$, can be approximately obtained by using the following equation [18].

$$
K_{1 \mathrm{cb}}=1.12 \sigma_{\mathrm{sb}}(\pi A)^{\frac{1}{2}}
$$

where $A$ is the crack length, appropriately equal to the thickness of carburized layer. It can be estimated from Fig. (3a) that value of $A$ is approximately $300 \mu \mathrm{m}$. Then $K_{1 \mathrm{Cb}}$ can be calculated out to be $29.4 \mathrm{MPa} \cdot \mathrm{m}^{1 / 2}$ according to equation (3). It is a relatively low value compared with that of general high-strength steel. Moreover, stress concentration is not taken into consideration. Therefore, it can be concluded that if there are numerous defects existing in the carburized layer, crack can easily be initiated in the carburized layer and propagate into the substrate under the stress induced by interference fit.

\section{CONCLUSION}

Results of this paper can be so summarized:

1. Microstructure, chemical composition and mechanic properties of the substrate of the unqualified drill bit differ little from that of the substrate of the qualified drill bit. They can meet the service requirements. It is not the substrate who should be responsible for the cracking.

2. The cracking failure should be attributed to the over-carburizing treatment which results in excessive defects in the carburized layer. Those defects act as stress raiser and initiate the crack easily. Then crack penetrates the carburized layer and propagates into the substrate and eventually lead to the failure.

\section{CONFLICT OF INTEREST}

The authors confirm that this article content has no conflict of interest.

\section{ACKNOWLEDGEMENTS}

The financial supports received from the National Key Technology R\&D Program in the 12th Five-Year Plan of China (Grant No. 2011BAK06B01-01) and the National Science and Technology Basic Project of the Ministry of Science and Technology of China (Grant No. 2012FY113000) are gratefully appreciated by the authors.

\section{REFERENCES}

[1] Olovsjo S, Johanson R, Falsafi F, Bexell U, Olsson M. Surface failure and wear of cemented carbide rock drill buttons-the importance of sample preparation and optimized microscopy settings. Wear 2013; 302: 1546-54.

[http://dx.doi.org/10.1016/j.wear.2013.01.078]

[2] Gupta A, Chattopadhyaya S, Hloch S. Critical investigation of wear behaviour of WC drill bit buttons. Rock Mech Rock Eng 2012; 46: $169-77$.

[http://dx.doi.org/10.1007/s00603-012-0255-9]

[3] Chiang LE, Elías DA. A 3D FEM methodology for simulating the impact in rock-drilling hammers. Int J Rock Mech Min Sci 2008; 45: $701-11$.

[http://dx.doi.org/10.1016/j.ijrmms.2007.08.001]

[4] Beste U, Jacobson S. A new view of the deterioration and wear of WC/Co cemented carbide rock drill buttons. Wear 2008; 264: 1129-41. [http://dx.doi.org/10.1016/j.wear.2007.01.030]

[5] Fan Y, Huang Z, Gao D, Li Q. Experimental study of an $\mathrm{Al}_{2} \mathrm{O}_{3} / \mathrm{WC}-\mathrm{Co}$ nanocomposite based on a failure analysis of hammer bit. Eng Fail Anal 2011; 18: 1351-8.

[http://dx.doi.org/10.1016/j.engfailanal.2011.03.028]

[6] Zhou Y, Huang Z, Zhang F, et al. Experimental study of WC-Co cemented carbide air impact rotary drill teeth based on failure analysis. Eng Fail Anal 2014; 36: 186-98.

[http://dx.doi.org/10.1016/j.engfailanal.2013.10.008] 
[7] Liu ZY. Zhai Gl, Dong CF, Li XG, Meng QK. Failure analysis on cracking of 40CrNiMo drill. Phys Exam Test 2007; 5: 1-7.

[8] Huang Z, Li Q, Zhou Y, et al. Experimental research on the surface strengthening technology of roller cone bit bearing based on the failure analysis. Eng Fail Anal 2013; 29: 12-26. [http://dx.doi.org/10.1016/j.engfailanal.2012.08.018]

[9] He C, Han L, Chen XB, Zhu HY. Study on the failure mechanism of air hammer bit. Drill Prod Technol 2010; 33: 134-7.

[10] Huang Z, Tan L, Jin X. Mechanical analysis and incline design of percussion-rotary drill bit side teeth. Geophys Equip 2007; $17:$ 87-91.

[11] Li SS, Wang ZQ, Ma DK. Kinematical analysis and failure mechanism of PDC bit cutter teeth. China Pet Mach 1997; 2: 17-9.

[12] Zhu H, Liu Q, Deng J, Wang G, Liao J. Rock-breaking mechanism of rotary-percussive drilling. J Basic Sci Eng 2012; 4: 622-31.

[13] Fu Y. The approach of improving the shatter-resistant capability of ball gear brazing head alloy teeth. Rock Drill Mach Pneumatic Tools 1988; 3: 38-43.

[14] Chen YQ, Pan SP, Zhou MZ, Yi DQ, Xu DZ, Xu YF. Effects of inclusions, grain boundaries and grain orientations on the fatigue crack initiation and propagation behavior of 2524-T3 Al alloy. Mater Sci Eng A 2013; 580: 150-8. [http://dx.doi.org/10.1016/j.msea.2013.05.053]

[15] Shimamura Y, Narita K, Ishii H, et al. Fatigue properties of carburized alloy steel in very high cycle regime under torsional loading. Int J Fatigue 2014; 60: 57-62. [http://dx.doi.org/10.1016/j.jfatigue.2013.06.016]

[16] Alfredsson B, Olsson E. Multi-axial fatigue initiation at inclusions and subsequent crack growth in a bainitic high strength roller bearing steel at uniaxial experiments. Int J Fatigue 2012; 41: 130-9. [http://dx.doi.org/10.1016/j.ijfatigue.2011.11.006]

[17] Lanoue F, Vadean A, Sanschagrin B. Finite element analysis and contact modelling considerations of interference fits for fretting fatigue strength calculations. Simul Model Pract Theory 2009; 17: 1587-602.

[http://dx.doi.org/10.1016/j.simpat.2009.06.017]

[18] Perez N. Fracture Mechanics. Germany: Springer 2015.

C) Tianliang et al.; Licensee Bentham Open

This is an open access article licensed under the terms of the Creative Commons Attribution-Non-Commercial 4.0 International Public License (CC BY-NC 4.0) (https://creativecommons.org/licenses/by-nc/4.0/legalcode), which permits unrestricted, non-commercial use, distribution and reproduction in any medium, provided the work is properly cited. 